\title{
The Influence of a Male Twin on Birthweight of its Female Co-twin - A Population-based Study
}

\author{
Ran D. Goldman', Efrat Blumrozen², and Isaac Blickstein² \\ ' Division of Emergency Medicine, The Hospital for Sick Children, Toronto, Ontario, Canada and Department of Pediatrics, \\ University of Toronto, Toronto, Ontario, Canada \\ ${ }^{2}$ Department of Obstetrics and Gynecology, Kaplan Medical Center, Rehovot, and the Hadassah-Hebrew University School of Medicine, \\ Jerusalem, Israel
}

\begin{abstract}
Eetal growth is influenced by various determinants, with - males being heavier than females. It was recently suggested that female birthweight tends to be increased by the presence of a male co-twin. We evaluated this hypothesis in the Israeli population. We reviewed a retrospective population database of the 1993-1998 Israeli Birth Registry. We compared male birthweight in the male-male and malefemale combination sets and female birthweight in the femalefemale and male-female combination sets. We compared the mean birthweight of males and females in three groups of total twin birthweight. The sample of 12,686 sets included $50.6 \%$ males. The male-male combination was found in $31.3 \%$ sets, female-female in $38.7 \%$ and unlike-sex combination in $30.0 \%$. A total twin birthweight of less than $3000 \mathrm{~g}$ was found in $7.2 \%$ sets, of $3001-5000 \mathrm{~g}$ in $50.7 \%$ sets, and of over $5000 \mathrm{~g}$ in $42.1 \%$ sets. The mean male birthweight was $2398 \pm 602 \mathrm{~g}$ and the mean female birthweight was $2316 \pm 566 \mathrm{~g}, p<.0001$ $(95 \% \mathrm{Cl}$ of 67,96$)$. The mean birthweight of males in the malemale combination was significantly lower than in the unlike-sex combination, $p<.0001$, in total birthweights over $3000 \mathrm{~g}$. No significant difference was found between the mean birthweight of females in the female-female and in the unlike-sex combinations in all total birthweight strata. Our findings do not substantiate a male-related inter-twin influence on female birthweight. Population differences might underlie the opposing observations in the literature.
\end{abstract}

Fetal growth is influenced by various determinants (Pilic et al., 1985). It is well known that males are heavier than females, a phenomenon seen in singletons (Anderson \& Brown, 1943) as well as in twins (Fakeye, 1986; Glinianaia et al., 2000; Glinianaia et al., 1998; Pilic et al., 1985;) and triplets (Elster et al., 1991; Jones et al., 1991). Recently, Glinianaia et al. (1998) studied cohorts of chorionic like- and unlike-sexed Norwegian twins and observed a tendency for female birthweight to be increased by the presence of a male co-twin. It was suggested that inter-twin relationship, involving mechanisms that influence birthweight of twins, might have implications not only for intrauterine life, but also might influence infancy, childhood and adulthood as well. For example, based on a distinct association between birthweight and antenatal estrogen exposure (Kaijser et al., 2000), it was suggested that hormonal exposure in utero influences the risk of breast cancer in later life (Trichopoulos, 1990). It was found that among females of unlike-sexed pairs, high birthweight constitutes a strong independent risk for breast cancer (Kaijser et al., 2001). Glinianaia et al. (1998) further suggested a close follow-up with respect to hormone-sensitive disorders and reproductive capability. Recently, Loos et al. (2001) found that within a given birthweight category, gestation of boys is shorter than that of girls, and this sex difference increases with decreasing birthweight. They suggested that boys grow at a faster pace than girls, but that girls catch up late in gestation.

To further test these hypotheses, we evaluated the influence of male presence on the birthweight of its female cotwin in the Israeli population.

\section{Participants and Methods}

We retrospectively reviewed the data of the Israeli Birth Registry obtained through the Central Bureau of Statistics, which includes, as required by law, all deliveries in Israel. The database of 12,785 twin pairs delivered during the period 1993-1998 has been used to select 12,699 (99.3\%) pairs with known birthweight and gender.

We used the designation of MF for one male and one female, FF for two female babies and MM for two male babies. We compared the male birthweight in the MM and MF combination sets and the female birthweight in the FF and MF combination sets. We compared the mean birthweight of males and females in three groups of total twin birthweight - less than 3000g, 3001-5000g, and 5001g or more.

The database was constructed by the Microsoft Excel ${ }^{\circledR}$ program and analyzed by the SPSS 8.0 statistical software. Comparisons between the mean birthweights were done by Student's $t$ test for independent samples. The sample size was large enough to detect differences of $5 \%$ at a power of $80 \%$. The $95 \%$ confidence interval of the mean difference

Address for correspondence: Ran D. Goldman, MD, Department of Paediatrics, The Hospital for Sick Children, 555 University Avenue, Toronto, Ontario M5G 1 X8 Canada.Email: ran.goldman@sickkids.ca 
was calculated. Two-tailed $p$ values less than .05 were considered significant.

\section{Results}

A total of 25,398 live newborns $(12,699$ twin sets) were included in the database. Thirteen were excluded due to insufficient data, hence 12,686 sets were included is the study. The mean (SD) birthweight was 2357 (586)g (range 480-5900g) and the mean $(S D)$ total twin birthweight was 4715 (1101)g (range 980-11170g). Of the newborns, $12,850(50.6 \%)$ were males and 12,522 (49.4\%) were females. A like-sex combination of MM was found in 3968 $(31.3 \%)$ sets, a combination of FF was found in 3805 $(30.0 \%)$, and unlike-sex twin combination was found in $4913(38.7 \%)$ sets. A total twin birthweight of less than $3000 \mathrm{~g}$ was found in $913(7.2 \%)$ sets, of $3001-5000 \mathrm{~g}$ in $6430(50.7 \%)$, and of over $5000 \mathrm{~g}$ in 5343 (42.1\%) sets.

The mean $(S D)$ male birthweight was 2398 (602)g and the mean $(S D)$ female birthweight was 2316 (566)g, $p<0.0001$ (95\% CI of 67,96$)$. However, when the total twin birthweights were analyzed, we found that in the $<3000 \mathrm{~g}$ group, the male and female birthweight was similar (1116 and $1114 \mathrm{~g}$ respectively, $p=0.87,95 \%$ CI 26, 30).
In the higher total twin birthweight group males were significantly heavier than females (Table 1).

The mean $(S D)$ birthweight of males in the MM combination was 2376 (612)g, significantly lower than the mean $(S D)$ weight in the unlike-sex combination: 2433 (584)g, $p<.0001$ (95\% CI 36,79). The mean male birthweight was significantly lower among same-sex compared to unlike-sex combinations except at the total birthweights less than 3000g (Table 2).

When the mean birthweight of females in the FF combination was compared to that in the unlike-sex combination, no significant difference was found: 2315 (568)g and 2317 (561)g respectively, $p=.83(95 \%$ CI 18,22$)$. The mean female birthweight was significantly higher among same-sex compared to unlike-sex combinations across the three levels of total twin birthweight (Table 3).

\section{Discussion}

Twins may be a good model to study the interplay between nature and nurture (Galton, 1875). Thus, fetal growth, which is the product of the relative influence of genetic composition (nature) and intrauterine environment (nurture), may be best evaluated in the twin gestation. The intrauterine period has

Table 1

Birthweight by Gender and by Total Twin Birthweight Group in the Israeli Population $(N=25,372)$

\begin{tabular}{|c|c|c|c|c|c|c|}
\hline Population total twin birthweight & Gender & $N$ & Mean & $(S D)$ & $p$ value & $95 \% \mathrm{Cl}$ \\
\hline up to 3000 & $\begin{array}{r}\text { Male } \\
\text { Female }\end{array}$ & $\begin{array}{l}953 \\
873\end{array}$ & $\begin{array}{l}1116 \\
1114\end{array}$ & $\begin{array}{l}(314) \\
(306)\end{array}$ & .874 & $-26,31$ \\
\hline $3001-5000$ & $\begin{array}{r}\text { Male } \\
\text { Female }\end{array}$ & $\begin{array}{l}6209 \\
6651\end{array}$ & $\begin{array}{l}2160 \\
2116\end{array}$ & $\begin{array}{r}(329) \\
(48)\end{array}$ & $<.0005$ & 32,55 \\
\hline over 5000 & $\begin{array}{r}\text { Male } \\
\text { Female }\end{array}$ & $\begin{array}{l}5687 \\
4999\end{array}$ & $\begin{array}{l}2872 \\
2792\end{array}$ & $\begin{array}{l}(382) \\
(336)\end{array}$ & $<.0005$ & 67,93 \\
\hline
\end{tabular}

\section{Table 2}

Birthweight of Male Newborns by Total Twin Birthweight Group in the Israeli Population $(N=6425)$

\begin{tabular}{|c|c|c|c|c|c|c|}
\hline Population total twin birthweight & Gender & $N$ & Mean & $(S D)$ & $p$ value & $95 \% \mathrm{Cl}$ \\
\hline \multirow[t]{2}{*}{ Up to 3000} & MF & 158 & 1143 & (309) & & \\
\hline & MM & 318 & 1102 & $(316)$ & .055 & $-1,83$ \\
\hline \multirow[t]{2}{*}{$3001-5000$} & $\mathrm{MF}$ & 1227 & 2195 & $(320)$ & & \\
\hline & MM & 1878 & 2136 & (333) & $<.0005$ & 42,75 \\
\hline \multirow[t]{2}{*}{ Over 5000} & MF & 1070 & 2897 & (352) & & \\
\hline & MM & 1774 & 2857 & $(345)$ & $<.0005$ & 22,59 \\
\hline
\end{tabular}

Table 3

Birthweight of Female Newborns by Total Twin Birthweight Group in the Israeli Population $(N=6261)$

\begin{tabular}{|c|c|c|c|c|c|c|}
\hline Population total twin birthweight & Gender & $N$ & Mean & $(S D)$ & $p$ value & $95 \% \mathrm{Cl}$ \\
\hline \multirow[t]{2}{*}{ Up to 3000} & $\mathrm{MF}$ & 158 & 1085 & (301) & & \\
\hline & $\mathrm{FF}$ & 278 & 1130 & (308) & .034 & 4,87 \\
\hline \multirow[t]{2}{*}{$3001-5000$} & MF & 1227 & 2089 & $(324)$ & & \\
\hline & $\mathrm{FF}$ & 2100 & 2133 & $(323)$ & $<.0005$ & 28,60 \\
\hline \multirow[t]{2}{*}{ Over 5000} & MF & 1070 & 2762 & (327) & & \\
\hline & $\mathrm{FF}$ & 1428 & 2814 & (342) & $<.0005$ & 33,70 \\
\hline
\end{tabular}


enduring effects on adult body size, but the question of whether these effects are genetic or environmental is still unresolved (Pietilainen et al., 2001). Fetal growth is probably determined by polygenic inheritance. The influence of the $\mathrm{Y}$ chromosome on fetal growth rate was already suggested in 1970 (Ounsted \& Ounsted, 1970) and kept researchers intrigued thereafter (James, 1999).

Male birthweight is higher than female birthweight in singletons (Anderson \& Brown, 1943), twins (Glinianaia et al., 2000; Glinianaia et al., 1998; Fakeye, 1986; Pilic et al., 1985) and triplets (Elster et al., 1991; Jones et al., 1991). The birthweight analyses of dizygotic unlike-sexed twins repeatedly showed a significantly higher mean birthweight of the male twin compared with its female co-twin (Blickstein \& Weissman, 1990; Pilic et al., 1985). Recently, Glinianaia et al. (2000) showed that male twins weighed consistently and significantly more than female twins throughout gestation (27 to 42 weeks). These observations suggest that a genetic component, presumably the $\mathrm{Y}$ chromosome, might have a special effect on fetal growth as it has on somatic development, body weight, bone maturation and teeth development (Pilic et al., 1985).

Gender combination is probably one of the factors determining gestational age as well (Bleker \& Hemrika, 1985; de Zegher et al., 1999; Elster et al., 1991; Malinowska et al., 1998). Within a given birthweight category boys were found to be consistently younger than girls and the age difference being most pronounced in the lower birthweight classes (de Zegher et al., 1999). Thus gender-related difference in fetal growth might be more pronounced before the third trimester and less marked towards term.

Birth order (first or second to be born) is probably another factor determining growth and subsequent birthweight of twins. A comparison of 71 male-female pairs with 82 female-male pairs showed similar mean twin birthweights and rates of discordance. However, males were significantly heavier compared with females in the male-first but not in the female-first combination. The rate of females being the smaller twins was significantly higher compared with males in both fetal sex combinations, leading to the conclusion that there might be an inter-twin, birth-order dependent, and gender influence on birthweight discordant pairs (Blickstein \& Weissman, 1990).

When analyzing the total twin birthweight according to fetal gender and parity, Malinowska et al. (1998) found that in both primiparous and multiparous mothers, male-male, female-female, and unlike-sex sets had different mean birthweights. Orelbeke et al. (1993) found that among 3069 dizygotic twins, birthweight was not affected by the gender of its co-twin. By contrast, Glinianaia et al. (1998) studied the influence of male presence on the birthweight of male and female unlike sex twins. Female birthweight was found to be higher in the presence of a male compared to a set of like-sex females. Male birthweight was higher when a female was present compared to same-sex male twin set. Although the birthweight difference was not statistically significant they assumed a tendency for the birthweight in females to be influenced by the presence of a male co-twin.

Recently, Loos et al. (2001) showed that birthweight of unlike-sex pairs was similar to that of female same-sex pairs; length of gestation in unlike-sex pairs was similar to that of female same-sex pairs and significantly longer than that of male same-sex pairs; and birthweight of girls from unlike-sex pairs was similar to that of girls from same-sex pairs; but boys from unlike-sex pairs weighed $78 \mathrm{~g}$ more than boys from same-sex pairs.

The study of Glinianaia et al. (1998) suggests a potential nurture-effect caused by the natural difference between males and females. Our results do not support their theory as well as the findings regarding birthweight found by Loos et al. (2001). As expected, males weighed more than females. We showed that male birthweight was higher when a female is present, and the total birthweight stratification suggests that this effect is not restricted to an earlier gestational age. However, when females' weight was analyzed in the whole population, no significant difference was noted if the co-twin was male or female. Categorizing the female's weight into three different total twin birthweights revealed that above $3000 \mathrm{~g}$ a significant difference in weight was found when a male co-twin was sharing the uterus (see Table 3). It is possible that twins delivered with a lower total birthweight (i.e., at an earlier gestational age) may not have the opportunity to express the inter-twin differences. In our cohort, this finding was revealed only in the above $3000 \mathrm{~g}$ female population and disappeared when the total twin birthweight of the population was examined. Further understanding of this unique phenomenon deserves more population studies.

Two plausible explanations could account for the differences in the result found by Glinianaia et al. (1998), by Loos et al. (2001) and in our population. First, different populations may have different gene pools, which could account for the differences between the Israeli, Norwegian and Flemish populations. Second, unlike Loos et al., we did not select pure dizygotic twins, but rather collected data from the entire twin population. Same-sex twin pairs consist of both monozygotics and dizygotics, the oppositesex twin pairs are all dizygotics. The data on which of the same-sex twin pairs were dizygotics was unavailable to us, hence a possible confounding factor might account for the observed differences. The question of whether selecting only dizygotic twins or differentiating between monochorionic and dichorionic pregnancies would affect birthweight, and in which direction, requires further research.

For the time being the opposing views do not substantiate a clear cut gender-related inter-twin influence on fetal growth. Further larger population-based studies, from different populations, are needed to evaluate this influence.

\section{References}

Anderson, N. A., \& Brown, E. W. (1943). Causes of prematurity. III. Influence of race and sex on duration of gestation and weight at birth. American Journal of Disease in Childhood, 65, $523-534$

Bleker, O. P., \& Hemrika, D. J. (1985). Gestational age according to fetal sex in twins. American Journal of Obstetrics \& Gyneco$\log y, 151,830-831$.

Blickstein, I., \& Weissman, A. (1990). Birthweight discordancy in male-first and female-first pairs of unlike-sexed twins. American Journal of Obstetrics \& Gynecology, 162, 661-663. 
de Zegher, F., Devlieger, H., \& Eeckels, R. (1999). Fetal growth: Boys before girls. Hormone Research, 51, 258-259.

Elster, A. D., Bleyl, J. L., \& Craven, T. E. (1991). Birthweight standards for triplets under modern obstetric care in the United States, 1984-1989. Obstetrics \& Gynecology, 77, 387-393.

Fakeye, O. O. (1986). Twin birthweight in Nigeria and the effect of sex-pair and parity. Tropical and Geographical Medicine, $38,265-270$.

Galton, F. (1875). The history of twins as a criterion of the relative powers of nature and nurture. Fraser's Magazine, 12, 566-576.

Glinianaia, S. V., Magnus, P., Harris, J. R., et al. (1998). Is there a consequence for fetal growth of having an unlike-sexed cohabitant in utero? International Journal of Epidemiology, 27(4), 657-659.

Glinianaia, S. V., Skjaerven, R., \& Magnus, P. (2000). Birthweight percentiles by gestational age in multiple births. Acta Obstetricia et Gynecologica Scandinavica, 79, 450-458.

James, W. H. (1999). Consequences of the sex difference in rates of fetal growth. Hormone Research, 52(3), 158.

Jones, J. S., Newman, R. B., \& Miller, M. C. (1991). Cross-sectional analysis of triplet birthweight. American Journal of Obstetrics \& Gynecology, 164, 135-140.

Kaijser, M., Granath, F., Jacobsen, G., et al. (2000). Maternal pregnancy estriol levels in relation to anamnestic and fetal anthropometric data. Epidemiology, 11, 315-319.
Kaijser, M., Lichtenstein, P., Granath, F., et al. (2001). In utero exposures and breast cancer: A study of opposite-sexed twins. Journal of the National Cancer Institute, 93(1), 60-62.

Loos, R. J. F., Derom, C., Eeckels, R., et al. (2001). Length of gestation and birthweight in dizygotic twins. Lancet, 358, 560-561.

Malinowska, K., Antosik, A., \& Balcerczak, M. (1998). The uterine capacity measured by the total twin birthweight and duration of twin pregnancy. Acta Geneticae Medicae et Gemellologiae (Roma), 47, 183-190.

Orelbeke, J. F., van Baal, G. C., Boomsma, D. I., et al. (1993). Birthweight in opposite sex twins as compared to same sex dizygotic twins. European Journal of Obstetrics and Gynecology \& Reproductive Biology, 50, 95-98.

Ounsted, C., \& Ounsted, M. (1970). Effect of Y chromosome on fetal growth-rate. Lancet, 2(7678), 857-858.

Pietilainen, K. H., Kaprio, J., Rasanen, M., et al. (2001). Tracking of body size from birth to late adolescence: Contributions of birth length, birthweight, duration of gestation, parents' body size, and twinship. American Journal of Epidemiology, 154, 21-29.

Pilic, Z., Sulovic, V., Markovic, S., et al. (1985). Genetic factors and fetal growth sex constitution and birthweight in twins. International Journal of Gynaecology \& Obstetrics, 23, 421-425.

Trichopoulos, D. (1990). Hypothesis: Does breast cancer originate in utero? Lancet, 335, 939-940. 